\title{
PREPARATION OF CATALYST SUPPORT FROM BIO CARBON
}

\author{
CAVALLARI, Roger Vasconcelos; DE LIMA, Natasha Beserra; SILVA, Júlio César Martins; \\ BERGAMASHI; Vanderlei Sergio; FERREIRA, João Coutinho*
}

Centro de Células a Combustível e Hidrogênio. Instituto de Pesquisa de Energia Nuclear, Av Prof. Lineu Prestes, 2242. Cidade Universitária, 05508-900 São Paulo - SP, Brasil.

*e-mail: jcferrei@ipen.br

Received 31 October 2017; received in revised form 30 January 2018; accepted 6 February 2018

\section{RESUMO}

O uso exagerado de recursos não renováveis, nas ultimas décadas, deflagrou consequências negativas para a sociedade, havendo necessidade de buscar soluções diante dos efeitos deletérios causados pelo avanço da devastação do meio ambiente. Visando contribuir com a ampliação das estratégias de controle de poluentes através do desenvolvimento de tecnologia de baixo custo, o presente trabalho tem como objetivo principal o desenvolvimento de materiais ativos com elevada resistência térmica e boa área especifica para adsorção e impregnação de metais. Neste sentido foram estudados três rotas de tratamento do biocarvão. $\mathrm{Na}$ caracterização do biocarbono usaram-se métodos analíticos como: Espectroscopia de Infravermelho (IV), Espectroscopia RAMAM, Medida da Área Superficial (BET), Análise Térmica (TG), Difração de Raios X (DRX) e Microscopia Eletrônica de Varredura (MEV). As diferentes condições de tratamento resultaram em mudanças na estrutura carbonácea do biocarbono com características adequadas para serem utilizados como suporte em catalisadores, apresentando sítios ativos com cargas negativamente carregadas para promover a fixação de metais em sua superfície. Verificou-se também um aumento na área superficial específica, variando entre 341,4 a $749,7 \mathrm{~m}^{2} \mathrm{~g}^{-1}$ e alterações nas bandas D e $\mathrm{G}$ do carvão e uma alta resistência à temperatura, o que promove reações catalíticas com baixa perda de catalisador.

Palavras-chave: Carvão Ativado; Catalisador; Hidrotermal.

\begin{abstract}
The overuse of non-renewables resources in the last decades has generated negative consequences for the society, which have boosting the search for mitigating the damage caused in the environment. Aiming to contribute to the expansion of the strategies to control the pollutants in the environment thought the development of low-cost technologies, the mean goal of present work is to develop active materials with high thermic resistance and suitable specific area to adsorption and impregnation of metals. In this regard, it was studied three different routes of treatment of the biocarbons. The biocarbons materials were characterized by infrared spectroscopy (IR), Raman spectroscopy, scanning electron microscopy (SEM), X-ray diffraction (XRD), thermogravimetric analysis (TG), and Brunauer-Emmett-Teller analysis (BET). The three different strategies of treatment resulted in changes in the carbonaceous structure of the biocarbon, resulting in suitable characteristics for support material for catalysts, such as activities sites with negative charge to promote the attachment of the metals on the carbon surface. It was also observed the enhancement of the specific surface area, that ranges from 341,4 to $749,7 \mathrm{~m}^{2} \mathrm{~g}^{-1}$, changes of $D$ and $G$ band of carbon and high temperature resistance, which promote catalytic reactions with catalyst loss.
\end{abstract}

Keywords: Activated Carbon; Catalyst; Hydro-thermal

PERIÓDICO TCHÊ QUÍMICA • www.periodico.tchequimica.com • Vol. 15 N. 30.

• ISSN 1806-0374 (impresso) • ISSN 1806-9827 (CD-ROM) • ISSN 2179-0302 (meio eletrônico)

(C) 2018. Porto Alegre, RS. Brasil 


\section{INTRODUÇÃO}

A população mundial abrange mais de 7,5 bilhões de pessoas, conforme dados divulgados pelo Departamento dos Assuntos Econômicos e Sociais das Nações Unidas (DESA) e da Organização das Nações Unidas (ONU) (DESA Population, 2017), de modo que este número chegará a níveis surpreendentes nos próximos anos, trazendo sérias preocupações para o desenvolvimento humano atual e futuro tais como alimentação, moradia, empregos, recursos energéticos, preocupações ambientais, dentre outros (Pimentel et al. 2006).

A crescente demanda por novos produtos e o aumento do crescimento populacional têm causado grandes impactos sobre 0 meio ambiente. Um marco histórico, que determinou uma mudança de comportamento em nossa sociedade foi à revolução industrial, a partir da qual surgiu uma série de avanços em vários ramos das indústrias elétrica, química e siderúrgica. Entretanto, após cada avanço e inovação, um novo tipo de resíduo sólido é gerado, impactando cada vez mais no meio ambiente (Leite, 2011).

Desta forma, surgiu a necessidade de se concentrar esforços para minimizar esses impactos. A transformação de resíduos sólidos em novos materiais de maior valor agregado se destaca como uma alternativa promissora para superar esses problemas (Ramos, 2014). O aproveitamento de resíduos apresenta, ainda, as vantagens de diminuir os custos de produção de diversos materiais, tais como, o carvão ativado (Park et al., 2002).

As aplicações do carvão ativado são inúmeras, inclusive como suporte catalítico usado em catalisadores, substituindo o carbono comercial, carbon blak, em sistemas catalíticos. Nestes sistemas a utilização de um suporte catalítico eficiente que apresente alta atividade, seletividade e estabilidade catalítica, além de um baixo grau de desativação são de fundamental importância (Alexiadis, 2007).

O presente trabalho tem como objetivo obter um suporte de carbono adequado, que apresente uma estrutura porosa e que permita uma alta taxa de permeação e afinidade com o metal a ser adsorvido (Rodriguéz, 1998). O emprego do suporte na confecção de catalisadores, além de promover uma maior dispersão da fase ativa, e controle das propriedades texturais, causa um efeito sinérgico que modifica as propriedades físico-químicas do sistema levando a um melhor desempenho catalítico, além disso, através da interação fase ativa/suporte o catalisador torna-se mais seletivo (Rodella, 2001).

\section{Carvão Ativado e Utilização como Suporte de Catalisadores}

O carvão ativado é considerado um adsorvente versátil que pode remover diferentes tipos de poluentes como íons metálicos, corantes, fenóis, detergentes, pesticidas, hidrocarbonetos clorados e muitos outros produtos químicos e organismos (Dermibas, 2005). Além disso, ele é também empregado na área de catálise, e suporte catalítico, podendo ser utilizado no preparo de catalisadores híbridos (suporte que apresenta atividade catalítica intrínseca), melhorando as propriedades catalíticas e a porosidade desses sistemas (Bhatnagara et al. 2010).

O carvão ativado é um material carbonáceo, que apresenta uma forma microcristalina, vem sendo utilizado, desde muito tempo, devido as suas propriedades únicas, tais como: alto grau de dureza, elevada resistência térmica em atmosfera inerte, alta resistência à corrosão, elevada condutividade elétrica, presença de grupos funcionais na superfície, facilidade em adsorver íons e elevada área superficial específica (Borowiecki et al.. 1998).

\section{PARTE EXPERIMENTAL}

A matéria prima utilizada para obter 0 carvão ativado foi a casca de coco da espécie nucifera, conhecido popularmente como coco da Baía. A parte mais externa do fruto, chamada epicarpo, possui casca lisa de coloração esverdeada quando jovem. Durante seu desenvolvimento, o epicarpo torna-se castanho e desprende-se da porção mediana do fruto, chamada mesocarpo, que é fibrosa. Quando o fruto seca, o mesocarpo desprende-se quase totalmente, restando sobre a parte mais interna do fruto (Cavalcanti, 2015; Magalhães, 2011).

A casca de coco foi separada do mesocarpo e seco ao ar livre. Em seguida, foi lavada com água destilada para a remoção de impurezas inorgânicas. A biomassa seca foi 
levada a estufa a $120^{\circ} \mathrm{C}$ por 24 horas. $\mathrm{Na}$ carbonização das amostras de endocarpo do coco da baía foi utilizada uma temperatura de carbonização de $900{ }^{\circ} \mathrm{C}$, para uma taxa de aquecimento de $10{ }^{\circ} \mathrm{C} \cdot \mathrm{min}^{-1}$ e um tempo de aquecimento de 40 minutos.

\subsection{Preparação da Amostra}

Para os procedimentos de retirada de impurezas solúveis do carvão usou-se solução de cloreto de amônio e fosfato de sódio com concentração de $0,1 \mathrm{~mol} . \mathrm{L}^{-1}$. Na ativação química usou-se $100 \mathrm{~mL}$ de $\mathrm{NH}_{4} \mathrm{OH}$ P.A, com agitação por $1,0 \mathrm{~h}$, filtrada e lavada com água destilada até a neutralização alcalina do carvão. Adicionou-se nitrato de amônio 2,05 mol. $\mathrm{L}^{-1}$ no material sob agitação em mesa agitadora microprocessada, marca Quimis modelo Q225M por 1,0 h, filtrado e lavado com água destilada. Em seguida adicionou-se $200 \mathrm{~mL}$ de solução de $\mathrm{HNO}_{3} 2,42 \mathrm{~mol} . \mathrm{L}^{-1}$, permanecendo em agitação por 1 hora, filtrado e secado em estufa a temperatura de $100{ }^{\circ} \mathrm{C}$, obtendo-se no final do processo o carvão de coco ativado quimicamente.

\subsubsection{Processo de Ativação do Coco}

No processo hidrotermal assistido por micro-ondas (HMO) foi utilizado para ativação do carvão de coco um forno de micro-ondas da marca Panasonic HMO-100, $800 \mathrm{~W}, 2,45 \mathrm{GHz}$ que possui autoclave com o copo de teflon inserido e acoplado no aparelho. O tratamento seguiu três rotas distintas de ativação descritas a seguir:

\section{Rota 1: Tratamento Térmico a $900^{\circ} \mathrm{C}$}

O biocarbono sem qualquer tratamento prévio foi colocado em um reator de teflon de 127 $\mathrm{mL}$, com a adição $120 \mathrm{~mL}$ de $\mathrm{HNO}_{3}$ 0,300 mol.L ${ }^{-1}$ e acoplado a um sistema hidrotermal assistido por micro-ondas nas condições de tempo de exposição à radiação eletromagnética de 15 a 25 minutos e com rampa de aquecimento de $10{ }^{\circ} \mathrm{C} /$ min até atingir a temperatura de $75^{\circ} \mathrm{C}$. O carvão obtido foi filtrado e secado em uma estufa a 100 ${ }^{\circ} \mathrm{C}$, para retirar a umidade. Após a secagem foi efetuado um tratamento térmico em um forno de calcinação com atmosfera controlada com fluxo de gás inerte (Argônio). Variou-se a temperatura do forno de ambiente até $900 \stackrel{\circ}{\circ}$ com rampa de aquecimento de $10^{\circ} \mathrm{C} / \mathrm{min}$.
Rota 2: Sem Tratamento Térmico e a pressão atmosférica

O biocarbono ativado quimicamente foi colocado em um reator de teflon de $127 \mathrm{~mL}$ com a adição de $120 \mathrm{~mL}$ de $\mathrm{HNO}_{3} 2,42 \mathrm{~mol} . \mathrm{L}^{-1} \mathrm{e}$ acoplado a um sistema hidrotermal assistido por micro-ondas nas condições de tempo de exposição à radiação eletromagnética de temperatura $75 \stackrel{\circ}{\circ}$, patamar de 45 minutos, rampa de aquecimento $10^{\circ} \mathrm{C} / \mathrm{min}$.

\section{Rota 3: Sem Tratamento térmico e com aplicação de pressão}

O biocarbono foi colocado em reator de teflon de $127 \mathrm{~mL}$, com a adição de $120 \mathrm{~mL}$ de $\mathrm{HNO}_{3} 2,42$ mol.L-1 , para tratamento hidrotermal, nas condições de temperatura de $120{ }^{\circ} \mathrm{C}$, patamar de 45 minutos, rampa de aquecimento de $10 \stackrel{\circ}{\circ} / \min$ e pressão dê $3,0 \mathrm{kgf} / \mathrm{cm}^{2}$. (Pressão gerada no reator após aquecimento e exposição à radiação sem qualquer meio de criação da mesma).

\subsubsection{Caracterização Físico-química das Amostras}

A caracterização microestrutural foi realizada por microscopia eletrônica de varredura. Foi utilizado um Microscópio eletrônico de Varredura da marca JEOL, modelo JSM 6010LA. A microscopia de varredura utiliza um feixe de elétrons que interage com os átomos da amostra a ser analisada, provocando espalhamento e emissão de vários tipos de radiação, sendo os elétrons secundários, os elétrons retroespalhados $e$ os raios $X$. Os elétrons retroespalhados fornecem informações sobre a composição do material, enquanto que os elétrons secundários informam sobre a morfologia, a topografia e a superfície da amostra. Os raios $X$ gerados pela mostra são utilizados para analisar elementos químicos, possibilitando detectar e quantificar os raios $X$ característicos por meio da microanálise, usando um detector de energia dispersiva de raios $X$ (EDX) ou (EDS), acoplado ao microscópio (Ramos, 2014).

As amostras de carvão foram caracterizadas por difração de raios $X$ (DRX) para identificar as estruturas cristalinas e os elementos presentes nas amostras. As condições de analises foram angulo de varredura em $2 \theta$ de $20^{\circ}$ a $70^{\circ}$ com passo de $0,05^{\circ}$ e 2 segundos de tempo de contagem. 
equipamento utilizado foi um Rigaku modelo Miniflex II operando a $30 \mathrm{KV}, 15 \mathrm{~mA}$ e radiação Cuka1 $(\lambda=1,5406 \AA)$.

Utilizou-se a técnica de analise térmica para avaliar o comportamento das curvas termogravimétricas (TGA) das amostras de carvão. Obteve-se as curvas termogravimétricas das amostras em um equipamento Setaram Labsys Evo em fluxo de ar sintético de $50 \mathrm{~mL}$ $\mathrm{min}^{-1} \mathrm{com}$ taxa de aquecimento de $10^{\circ} \mathrm{C} \mathrm{min}^{-1}$ de rampa a partir da temperatura ambiente até 800 ${ }^{\circ} \mathrm{C}$ (pirolise).

A área superficial das amostras de carvão foi analisada, pelo método de adsorção gasosa (método BET). Utilizou-se o equipamento da marca Quantachrome, modelo ChemBET 3000 e a porosidade a partir da desorção e adsorção de $\mathrm{N}_{2}$ a $77 \mathrm{~K}$. Esta técnica de analise consiste na medida das alterações sofridas por uma mistura de nitrogênio e hélio, quando a amostra é submetida a variações de temperatura de trabalho do nitrogênio liquido.

A técnica de espectroscopia de adsorção no infravermelho FTIR consiste na identificação de grupos funcionais da formação de diferentes compostos. Utilizou-se um equipamento Digilab Excalibur-FT3000, na região do infravermelho na faixa de 1000 a $4000 \mathrm{~cm}^{-1}$.

A análise por espectroscopia Raman foram realizados num equipamento MacroRam Horiba. As amostras foram expostas a laser a 10 $s$ onde em cada etapa de analise foi resfriada com $\mathrm{N}_{2}$ até a temperatura de $70{ }^{\circ} \mathrm{C}$. O espectro da rede cristalina do carvão foi estudado para obter informações sobre a ordem estrutural de material carbonoso correspondente ao pico $G$ (grafite) que se encontra na região $1580 \mathrm{~cm}^{-1}$ devido aos modos vibracionais presentes em todas as ligações $\mathrm{C}=\mathrm{C}$, ou seja, está presente em todas as formas $\mathrm{sp}^{2}$ e permite observar as vibrações simétricas nos anéis de carbono, já o pico $D$ (desordem), está relacionado às ligações tipo $\mathrm{sp}^{2}$ referentes ao modo vibracional tipo respiração dos anéis mostrando a simetria na borda espacial da estrutura do carbono.

\section{RESULTADOS E DISCUSSÃO}

\subsection{Microscopia Eletrônica de Varredura}

A Figura 1 mostra as imagens da matriz do carvão de coco, ou seja, sem tratamento de ativação, (Fig. 1a), apresentando uma morfologia bastante distinta e fragmentada como telhas quebradas e alongadas. $\mathrm{Na}$ micrografia apresentado pelo método de ativação hidrotermal, rota 1 , Fig. $1 \mathrm{~b}$ pode se observar que o tratamento produziu uma superfície mais porosa e irregular, porém mais quebradiço, mas mantendo a superfície externa da matriz carbonácea integra com uma pequena formação de um bloco. De acordo as imagens do carvão (Fig 1c), o tratamento hidrotermal realizado pela rota 2, provocou modificações significativas em suas faces, apresentando aspectos de blocos afunilados mantendo a superfície carbonácea integra e a face externa porosa mostrando que a ativação hidrotermal assistida por micro-ondas ocorreu de dentro para fora, mas ainda possui algumas partes fragmentadas em seu interior, formando janelas abertas como blocos estilhados.

A imagem do carvão ativado pelo tratamento hidrotermal pela rota 3 (Fig. $1 \mathrm{~d}$ ) tem um aspecto de blocos sobrepostos e com menos fragmentos expostos, mantendo a porosidade intacta e a integridade textural do carvão, apresentando suas estruturas definidas na forma de blocos e que o efeito do tratamento nas faces ficou mais evidente na parte interna, apresentando melhor morfologia para adsorção de metais.

Os resultados obtidos por EDS são apresentados na Tabela 1. Observa-se que houve um aumento no teor de oxigênio na superfície do carvão e uma diminuição no teor de carbono nas amostras, principalmente na amostra de carvão ativado pela rota 3 de ativação hidrotermal, indicando maior funcionalidade. $O$ oxigênio é 0 principal heteroátomo que aparece na rede de carbono, presente principalmente nos grupos funcionais carbonila, carboxila, hidroxila e enóis. Estes grupos superficiais influenciam a reatividade e as propriedades de adsorção do material que permite maior facilidade de impregnação de vários compostos, orgânicos e inorgânicos (Guimarães, 2008). 
Tabela 1. Porcentagem de carbono e oxigênio obtido por EDS do Carvão ativado tratado por ativação hidrotermal

\begin{tabular}{c|c|c}
\hline Amostra & $\begin{array}{c}(\%) \text { de } \\
\text { Carbono }\end{array}$ & $\begin{array}{c}(\%) \text { de } \\
\text { Oxigênio }\end{array}$ \\
\hline Matriz & 87,98 & 12,02 \\
Rota 1 & 85,32 & 14,69 \\
Rota 2 & 84,78 & 15,22 \\
Rota 3 & 79,20 & 20,80 \\
\hline
\end{tabular}

\subsection{Difração de Raios-X}

A Figura 2 apresenta os resultados de DRX do carvão de coco após os processos de ativação. Os resultados de Difração de raios $-X$ mostram a presença de dois halos amorfo na condição de $20^{\circ}$ a $90^{\circ}$ em 2 segundos de parada entre os ângulos e os perfis da difração são praticamente iguais. Observa-se que dois halos amorfos em aproximadamente em 25, 32, 36 , que podem estar (estão relacionados) relacionados ao carbono grafítico.

A amostra do carvão sem ativação apresenta uma estrutura amorfa e não demonstram picos cristalinos na amostra, podendo conter estruturas nanométricas ou metais ocultos pela matriz amorfa do carvão.

\subsection{Medida da área superficial especifica}

A Tabela 2 apresenta os resultados da área superficial especifica das amostras de carvão ativado obtidos pelos diferentes métodos de preparação. Pode-se observar que o processo de carbonização/ativação com aumento de pressão de vapor favoreceu a um aumento na área superficial. Isto pode ser explicado pelo fato de que o material sobre o vapor produzido pelas micro-ondas conduz a uma estrutura mais estável termicamente que, por sua vez, promove uma lenta gaseificação, no interior da partícula, resultando na elevação da microporosidade durante a ativação da amostra.

Tabela 1. Resultados da Área Superficial Especifica BET

\begin{tabular}{cc}
\hline Amostra & Área Superficial Específica $\left(\mathrm{m}^{2} \mathrm{~g}^{-1}\right)$ \\
\hline Matriz & 539,3 \\
\hline Rota 1 & 341,4 \\
\hline Rota 2 & 622,7 \\
\hline Rota 3 & 749,7 \\
\hline
\end{tabular}

\subsection{Termografia Gravimétrica}

Apresenta-se na Figura 3 o resultado da análise termogravimétrica do carvão nas diferentes metodologias de ativação hidrotermal assistida por micro ondas. A análise da curva TG permite determinar a temperatura mais adequada para as etapas de ativação, carbonização e no estudo de adsorção de metais no carvão para uso como suportes catalíticos em células a combustível.

Nota-se a perda de massa, em duas etapas, em todas as amostras de carvão, a 100,2 ${ }^{\circ} \mathrm{C}$ e a partir de $519,3{ }^{\circ} \mathrm{C}$ referente a perda de massa água e respectivamente. Observa-se uma perda de massa gradual até $779,2{ }^{\circ} \mathrm{C}$ na matriz do coco.

No tratamento da amostra de ativação que foi realizado a $900{ }^{\circ} \mathrm{C}$ em forno em fluxo de Argônio inicia-se em $90,6{ }^{\circ} \mathrm{C}$, ocorrendo uma nova queda em $181,4{ }^{\circ} \mathrm{C}$ e a partir de $476{ }^{\circ} \mathrm{C}$ há perda de massa se estendendo até $732,8^{\circ} \mathrm{C}$. $\mathrm{O}$ carvão ativado pelo método hidrotermal 2, apresentou um baixo teor de perda de massa em $103,3{ }^{\circ} \mathrm{C}$ e a partir de $507,2{ }^{\circ} \mathrm{C}$ uma perda gradual até atingir a temperatura de $806,5^{\circ} \mathrm{C}$. Na amostra do carvão ativado pelo método hidrotermal 3 a perda de massa inicia-se a 110,9 ${ }^{\circ} \mathrm{C}$ e a partir de $489,5^{\circ} \mathrm{C}$ gradualmente há perda de massa até $770^{\circ} \mathrm{C}$.

Com o aumento da temperatura ocorre A decomposição do carvão sugere a presença de óxidos ou resíduos inorgânico (cinzas) e umidade, além de possibilitar visualizar que entre 470 a $520{ }^{\circ} \mathrm{C}$ apresenta a degradação térmica e ao elevar a temperatura ocorre a combustão do carvão não apresentando estabilidade na perda de massa continuando até extingui-la. O baixo teor de cinzas é um fator desejável, pois a presença de cinzas pode afetar o comportamento adsortivo dos carvões ativados (Medeiros, 2008; Fernandez, 2011).

\subsection{Espectroscopia na região do infravermelho dos catalisadores}

Os espectros de FTIR do carvão de coco são apresentados nas Figuras 4. As principais frequências vibracionais do carvão de coco e as possíveis espécies existentes no carvão para avaliação dos métodos de preparação e comparação entre as três rotas sugeridas neste trabalho. 
Observa-se na Figura 4 que todas as amostras analisadas apresentaram perfis semelhantes. $\quad \mathrm{Na}$ matriz, sem passar por qualquer ativação, mostrou a presença de uma banda entre 3788 e $3662 \mathrm{~cm}^{-1}$ e em 3914,3710 e $3657 \mathrm{~cm}^{-1}$ na amostra tratada pelo método hidrotermal 2, na amostra hidrotermal 3 nas bandas entre 3914 e $3646 \mathrm{~cm}^{-1}$ correspondem às vibrações de estiramento $\mathrm{O}-\mathrm{H}$ dos grupos fenólicos (Ramos, 2014; Bandosz, 2006).

A banda centrada em $3040 \mathrm{~cm}^{-1}$ (matriz) e $2.726 \mathrm{~cm}^{-1}$ que aparecem nas amostras da matriz e no tratamento pelo método hidrotermal 3 sugere que seja 0 estiramentos vibracionais simétricos e assimétricos de grupos $-\mathrm{CH}_{2} \mathrm{e}-\mathrm{CH}_{3}$ (metilas e metilenos) (Castro, 2009). A presença de banda aproximadamente em $1606 \mathrm{~cm}^{-1}$ pode ser atribuída às vibrações de anéis aromáticos típicos de materiais carbonáceos $\mathrm{C}=\mathrm{O}$ (Castro, 2009; Pereira et al. 2008), e entre 1648 e 1650 $\mathrm{cm}^{-1}$ nas amostras são características ao estiramento vibracional da ligação $\mathrm{C}=\mathrm{C}$ de grupos quinônicos (Ramos, 2014; Guilarduce et al. 2006). O estiramento antissimétrico ocorre usualmente entre 1650 e $1540 \mathrm{~cm}^{-1}$ e o simétrico entre 1450 e $1360 \mathrm{~cm}^{-1}$ (Boonamnuayvitaya et al. 2004).

As bandas associadas a $1470 \mathrm{~cm}^{-1}$ nas amostras da matriz e hidrotermal 3 são características do estiramento vibracional da ligação N-H (Boonamnuayvitaya et al. 2004). A presença da banda entre 2.160 a $1967 \mathrm{~cm}^{-1}$ é atribuída aos grupos azidas - $\mathrm{N}=\mathrm{N}=\mathrm{N}$, nestas regiões é associada às vibrações de deformação axial de duplas ligações (não acumuladas) e deformações angulares de $\mathrm{N}-\mathrm{H}$ e $\quad-\mathrm{NH}_{2}$ (Boonamnuayvitaya et al. 2004).

Nas regiões entre 1045 nas amostras de hidrotermal 1 indica estiramento vibracional da ligação O-H (Mourão et al. 2010). O espectro desta amostra também apresentou duas outras bandas entre as regiões de 1542 e $1513 \mathrm{~cm}^{-1}$, sendo que a primeira pode ser associada a presença ao grupo dos carbonatos e a segunda pode estar associada a vibrações de grupos aromáticos, obscurecida pela banda de 1560 de aromáticos, podendo também caracterizar aminas e aminas secundárias (Mourão et al. 2010; Boonamnuayvitaya et al. 2004).

\subsection{Espectroscopia RAMAM}

Os espectros Raman dos carvões ativados, obtidos a partir das amostras, estão apresentados na Figura 5. As curvas apresentaram perfis semelhantes, com duas bandas em aproximadamente 1330 e $1585 \mathrm{~cm}^{-1}$, atribuídas às bandas $D$ e $G$, respectivamente, que são características de materiais carbonáceos.

\section{CONCLUSÕES}

A partir dos resultados apresentados pode-se concluir que as rotas propostas para ativação do carvão demonstram características diferentes e que se destacam como promissores adsorverdores podendo ser aplicado também como suporte catalítico a base de biocarbonos. As analises destacam uma mudança na estrutura do carbono evidenciando a formação de tunelamentos na estrutura do carvão aumentando os grupos oxigenados favorecendo a aplicação de adsorção de metais. Verificou-se também um aumento da área superficial específica de 341,4 to $749,7 \mathrm{~m}^{2} \mathrm{~g}^{-1}$, do tratamento 1 para o tratamento 3 .

Esse suporte apresenta ótima estabilidade térmica o que proporciona seu uso para reações que exigem altas temperaturas, resistindo em até $800^{\circ} \mathrm{C}$ o que se torna um produto viável. Possui alta área superficial especifica $\left(749,7 \mathrm{~m}^{2} \mathrm{~g}^{-1}\right)$ e a ativação hidrotermal apresentou uma estrutura porosa, com aumento do volume de microporos observadas nas diferentes rotas utilizadas. Com esses dados nota-se que o suporte proposto tem muitas qualidades a serem observadas no processo de preparação de catalisadores utilizando biomassa como suporte o que pode ser economicamente viável e acessível para sínteses de catalisadores pilotos.

\section{AGRADECIMENTOS}

Os autores agradecem ao CNPq pelo apoio aos bolsistas de iniciação científica e ao Projeto Temático FAPESP $n^{\circ}$ 2014/09087-4 pelo apoio financeiro. 


\section{REFERÊNCIAS}

1. DESA POPULATION DIVISION. World Population Prospect 2017. Disponível em: https://esa.un.org/unpd/wpp/. Acessada em Agosto de 2017.

2. PIMENTEL D.; PIMENTEL M.; Global environmental resources versus world population growth. Ecological economics, 2006, v. 59, p. $195-198$.

3. LEITE, A. D. Brevíssima revisão histórica. In: A Economia Brasileira - De Onde Viemos e Onde Estamos. 2a ed. Rio de Janeiro: Editora Campus/Elsevier, 2011, Cap. p. 3-15.

4. RAMOS, M. S. Obtenção de carvões ativados a partir de resíduos industriais e agrícolas. Dissertação de PósGraduação, Universidade Federal da Bahia, Salvador, 2014.

5. PARK, S. J.; JUNG, W. Y. Preparation and structural characterization of activated carbons based on polymeric resin. Journal of Colloid and Interface Science, 2002, v. 250, p. 196-200.

6. ALEXIADIS A.; Global warming and human activity: A model for studying the potential instability of the carbon dioxide/temperature feedback mechanism. Ecological modeling, 2007, v. 20 3, p. 243-256.

7. RODRIGUEZZ-REINOSO, $\mathrm{F}$. The role of carbon materials in heterogeneous catalysis, Carbon, 1998, v. 36, n. 3, p. 159-175.

8. RODELLA C. B. Preparação e caracterização de catalisadores de $\mathrm{V}_{2} \mathrm{O}_{5}$ suportados em $\mathrm{TiO}_{2}$. Tese Doutorado, Universidade de São Paulo, São Carlos, 2001.

9. DERMIBAS A; Potential applications of renewable energy sources, biomass combustion problems in boiler power systems and combustion related environmental issues. Progress in Energy and Combustion Science, 2005, v. 31, p. 171-192.

10. BHATNAGARA, A.; SILLANPÄÄ, M. Utilization of agro-industrial and municipal waste materials as potential adsorbents for water treatment $-A$ review, Chemical Engineering Journal, 2010, v. 157, p. 277-296.

11. CAVALCANTE, V. R. Produção de carvão ativado a partir de resíduo de coco, banana e laranja. Dissertação de
Mestrado em Desenvolvimento de Processos Ambientais, Universidade Católica de Pernambuco, Pernambuco, 2015.

12. MAGALHÃES, V. H. P.; NEVES, M. A. F. S. Utilização do pericarpo de coco verde (Cocos Nucifera L. - Arecaceae) para a remoção de resíduos de íons cromo (VI) em soluções aquosas, Perspectivas da Ciência e Tecnologia, 2011, v.3, n. 1/2, pag. 10-16,

13. GUIMARÃES, I. S. Oxidação de carvões ativados de endocarpo de coco da baía com soluções de HNO3 e uma investigação sobre o método de Boehm. João Pessoa. Programa de PósGraduação em Química, UFPB, Dissertação de Mestrado, 63p, 2008.

14. MEDEIROS, L.L. Remoção de cobre (II) de soluções aquosas por carvões ativados de bagaço de cana-de-açúcar e endocarpo de coco da baía isentos de tratamentos químicos superficiais. Tese de Doutorado, Programa de PósGraduação em Química, UFPB, João Pessoa, 2008.

15. FERNANDES, S. J. Catalisadores de paládio suportado em carvão ativado para produção de biocombustíveis. Dissertação de Mestrado, Universidade Federal da Paraíba, João Pessoa, 2011.

16. BANDOSZ, T.J. Activated carbon surfaces in environmental remediation. New York, Ed. ELSEVIER, 2006, 7 v. 571 p.

17. CASTRO, C. S. de. Preparação de carvão ativado a partir de borra de café: uso como adsorvente e como suporte catalítico para remoção de poluentes orgânicos em meio aquoso. Dissertação Mestrado em Agroquímica, 92 p., Universidade Federal de Lavras, Lavras, 2009.

18. PEREIRA, e.; OLIVEIRA, L.C.A.; VALLONE, A.; SAPAG,K.; PEREIRA, M. Preparação de carvão ativado em baixas temperaturas de carbonização a partira de café: utilização de $\mathrm{FeCl}_{3}$ como agente ativante. Química Nova, São Paulo, 2008, v. 31 , n. 6 , p. $1296-1300$.

19. GUILARDUCI, V.V.; MESQUITA, J.P.; MARTELLI, P.B.; GORGULHO, H.F. Phenol adsorption on commercial active carbon under alkaline conditions. Quim. Nova. 2006, 29: 1226. 
20. BOONAMNUAYVITAYA, V.; CHAIYA, C.; TANTHAPANICHAKOON, S. J.The Preparation and Characterization of Activated Carbon from Coffee Residue. Chem. Eng. JPN. 2004, 37: 1504.

21. MOURÃO, P.A.M.; LAGINHAS, C.; CUSTÓDI, F.; NABAIS, J.M.V.; CARROTT, P.J.M.; CARROTT, M.M.L.R. Influence of oxidation process on the adsorption capacity of activated carbons from lignocellulosic precursors", Fuel Processing Technology, 2010, 92, 2: 241 $-246$. 

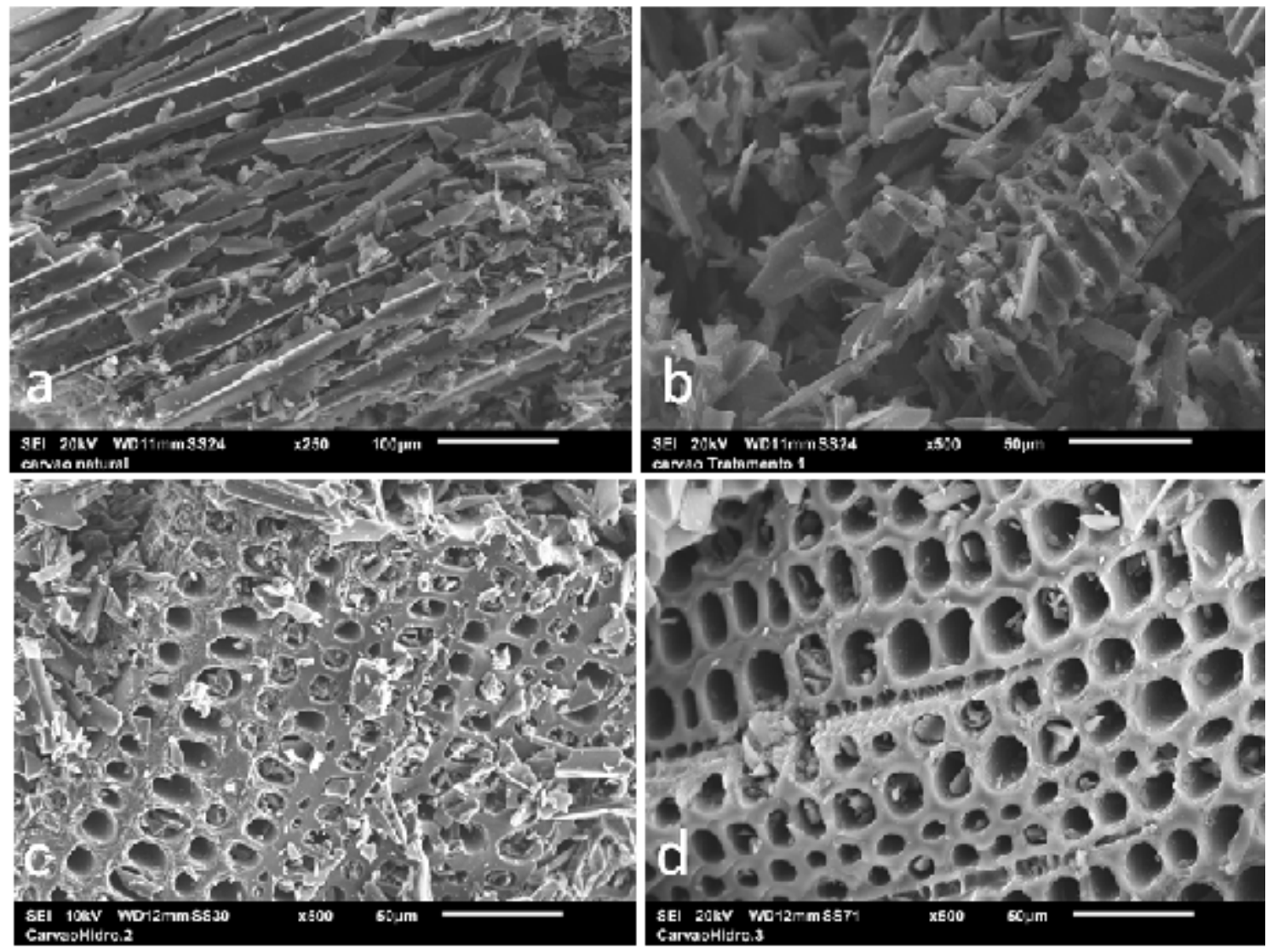

Figura 1. Micrografia Eletrônica de Varredura da amostra de carvão tratado pelo sistema hidrotermal assistido por micro-ondas (HMO) (a) matriz, (b) método 1,(c) método 2,(d) método 3

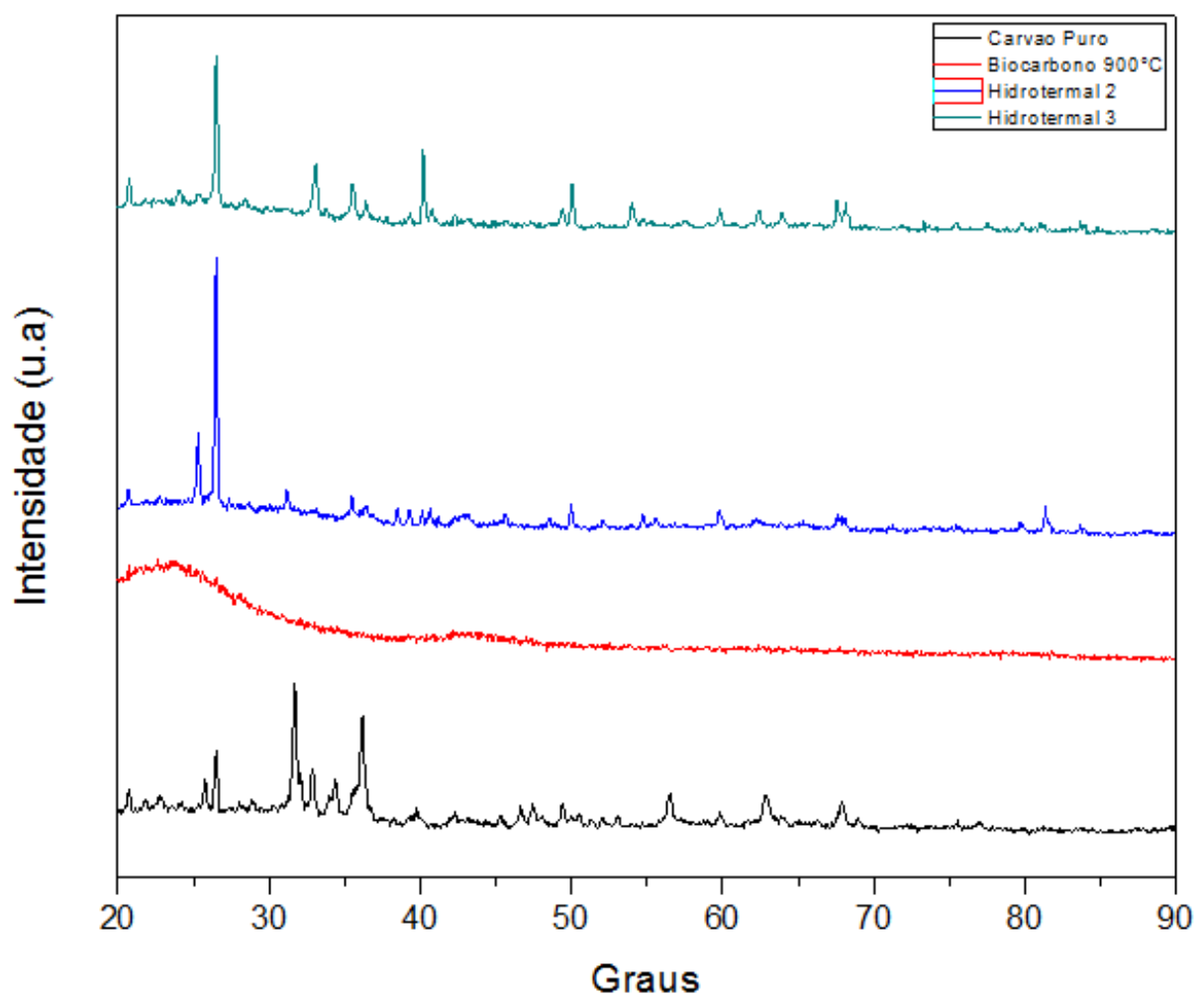

Figura 2. Difratograma de raios- $X$ das amostras de carvões 

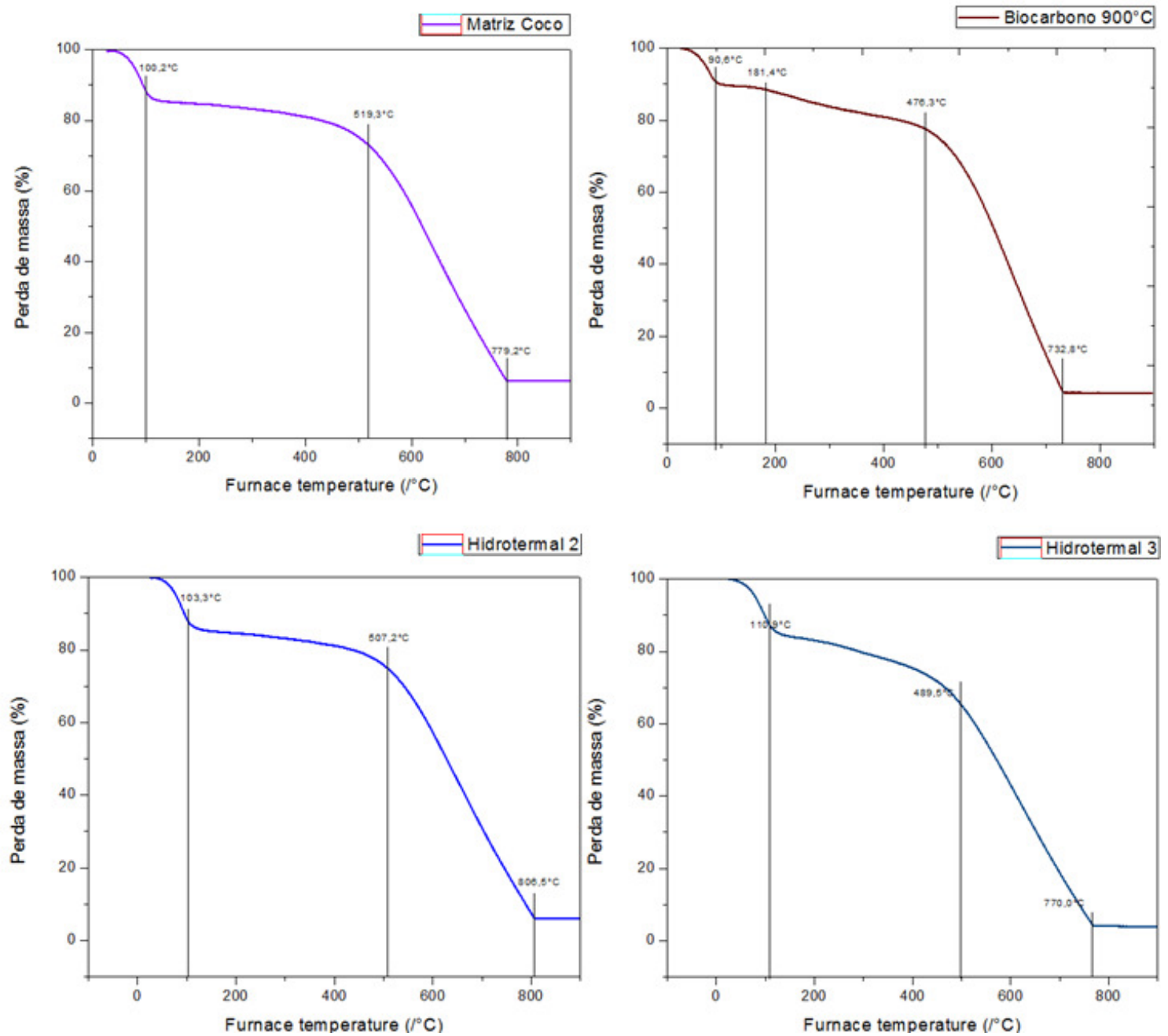

Figura 3. Analise de Termogravimetria do biocarbono nos métodos de ativação 

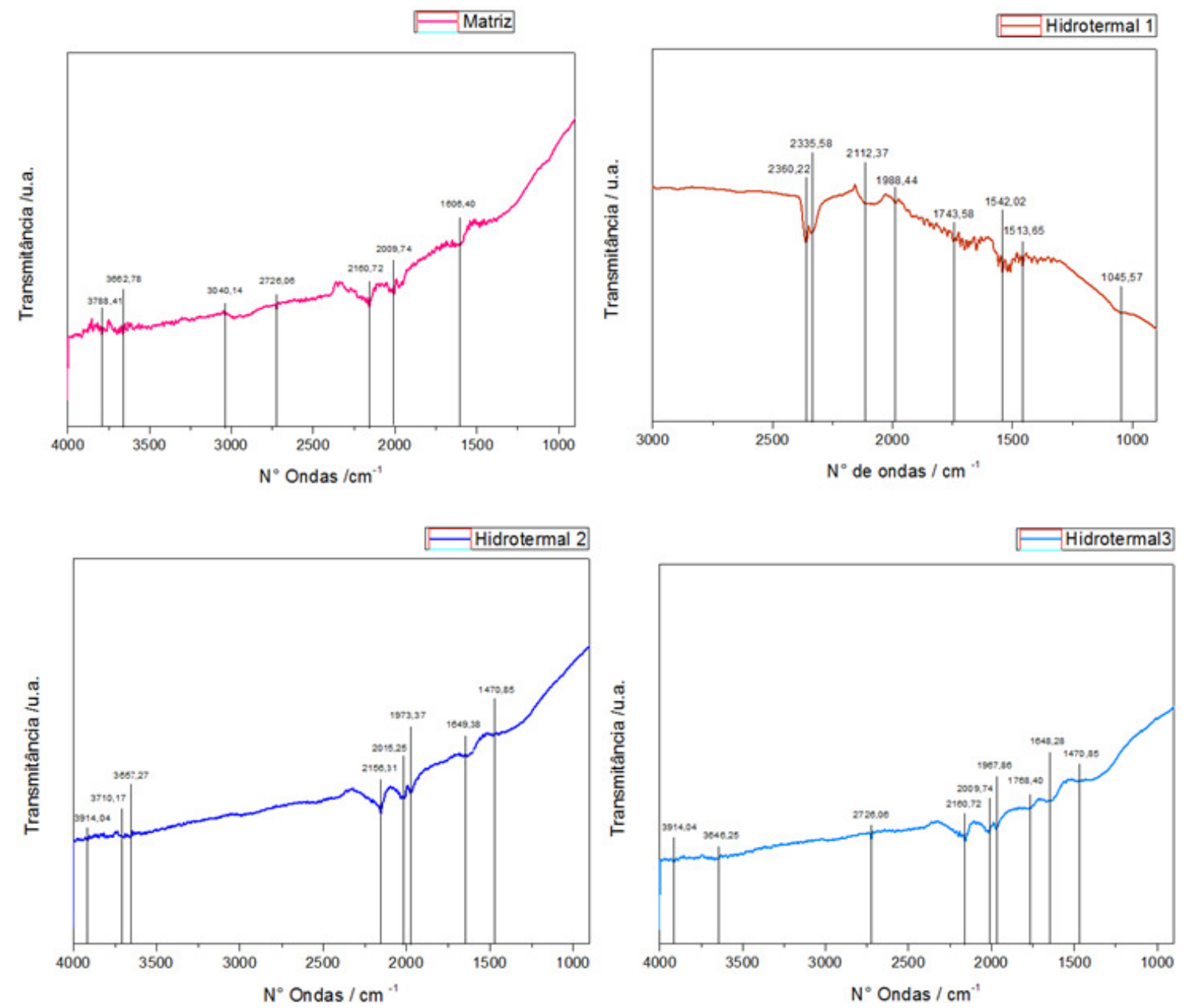

Figura 4. Analise de Espectroscopia na região do infravermelho no carvão de coco 

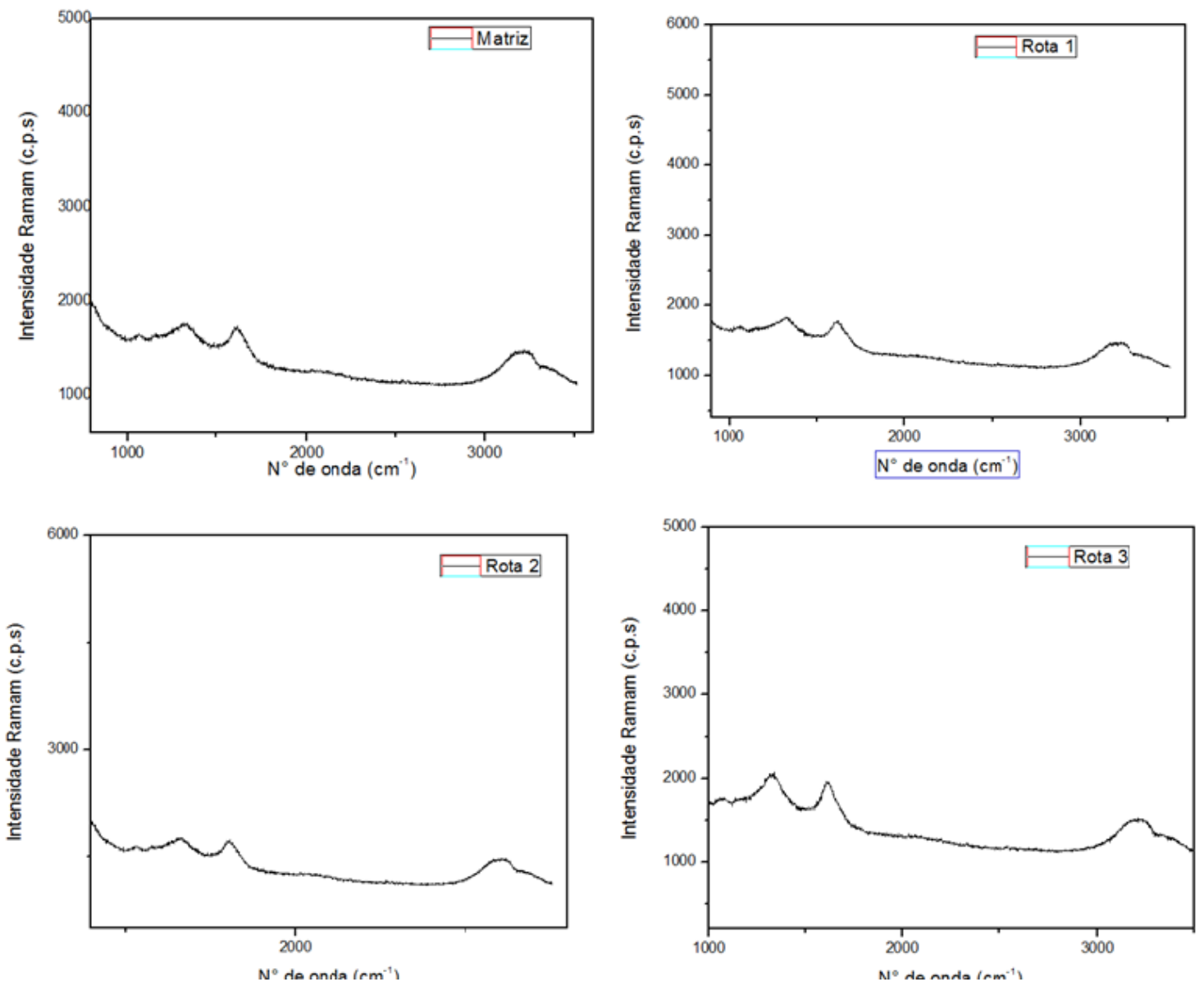

Figura 5. Analise de Espectroscopia RAMAM

PERIÓDICO TCHÊ QUÍMICA • www.periodico.tchequimica.com • Vol. 15 N. 30.

- ISSN 1806-0374 (impresso) • ISSN 1806-9827 (CD-ROM) • ISSN 2179-0302 (meio eletrônico)

(C) 2018. Porto Alegre, RS. Brasil

The Periódico Tchê Química (ISSN: 1806-0374; 2179-0302) is an open-access journal since 2004. Journal DOI: 10.52571/PTQ. http://www.tchequimica.com. This text was introduced in this file in 2021 for compliance reasons.

(c) The Author(s)

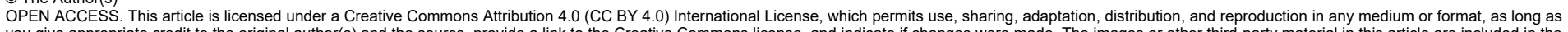
you give appropriate credlt ine original autho(s) and he source, provide a link to the Crealive Commons license, and indicate if changes were made. The images or other third-party material in this article are included in the article 's Creative Commons license unless indicated otherwise in a credit line to the material. If material is not included in the article's Creative Commons license and your intended use is not permitted by statutory regulation or exceeds the permitted use, you will need to obtain permission directly from the copyright holder. To view a copy of this license, visit http://creativecommons.org/licenses/by/4.0/. 